\title{
Violência vivida: a dor que não tem nome
}

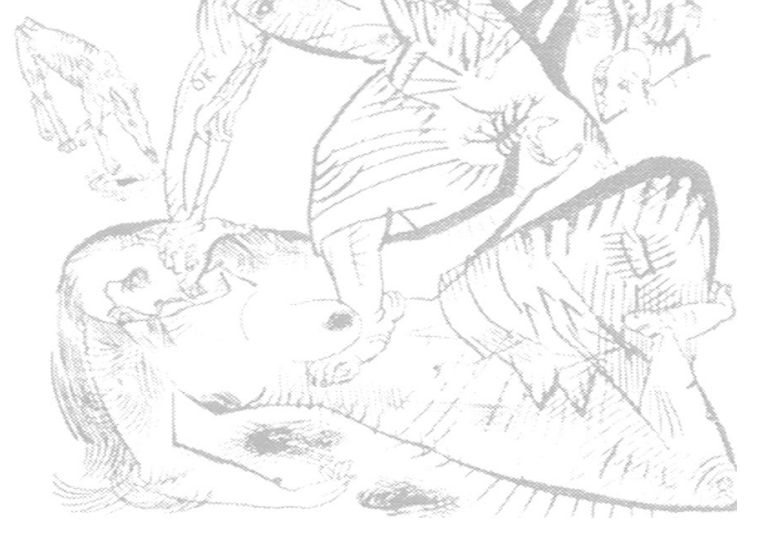

Lilia Schraiber

Ana Flávia d'Oliveira Heloísa Hanada Wagner Figueiredo Márcia Couto Lígia Kiss Júlia Durand Adriana Pinho ${ }^{1}$

SCHRAIBER, L. et al. Violence experienced: the nameless pain, Interface - Comunic, Saúde, Educ, v.7, n.12, p.41-54, 2003.

The account of the violence that women undergo is a difficult one. One is dealing with the invisibility of violence affecting users of care services and professionals, which gives rise to communication impasses. The authors attempted to characterize this silence by studying users of primary care in the São Paulo public network as regards the prevalence of violence, the perception of having suffered violence, the definition of violence in general and the designation given by the person who experienced violence. 322 users aged 15 to 49 were interviewed concerning physical, sexual and/or psychological aggression, the aggressor, and the perception of having suffered violence. The interviewees were asked to tell the interviewer about a striking episode, as well as what they would call it and what their definition of violence would be. $69.6 \%$ of the interviewees referred to some physical, psychological or sexual aggression; of these, $63.4 \% \%$ did not consider that they had undergone violence in life; $64.3 \%$ told of some striking episode and $46.5 \%$ of them gave a name to the experience. The most common definition of violence was physical aggression (78.8\%), followed by psychological aggression (39.7\%) and sexual aggression (24.2\%). One concludes that most women that referred to some aggression did not consider that they had suffered violence in life. They had great difficulty in narrating their episodes and giving them names and, even though most of these episodes had taken place within the domestic sphere, in the definition of violence this reference was omitted.

KEY WORDS: Communication; violence; invisibility of violence; domestic violence; violence against women.

É difícil o relato de violência sofrida por mulheres. Trata-se da invisibilidade da violência que afeta as relações usuárias - profissionais, criando impasses comunicacionais. Buscou-se caracterizar este silêncio, estudando usuárias de atenção primária na rede pública de São Paulo, quanto a prevalência de violência, a percepção de ter sofrido violência, a definição de violência em geral e a nomeação dada por quem a experimentou. Entrevistaram-se 322 usuárias de 15 a 49 anos, sobre agressões física, sexual e/ou psicológica, o agressor, e a percepção de ter sofrido violência, solicitando-se o relato de um episódio marcante, o nome que daria a este e a definição de violência em geral. Das entrevistadas, $69,6 \%$ referiram alguma agressão física, psicológica ou sexual e, destas, $63,4 \%$ não consideraram haver sofrido violência na vida; $64,3 \%$ relataram algum episódio marcante e 46,5\% atribuíram um nome ao vivido. A definição de violência mais comum foi a de agressão física $(78,8 \%)$, seguida pela psicológica $(39,7 \%)$ e sexual $(24,2 \%)$. Conclui-se que a maioria das mulheres que referiu alguma agressão não considerou haver sofrido violência na vida. Houve grande dificuldade em contar episódios e nomeá-los, e apesar de a maioria desses episódios serem do âmbito doméstico, na definição de violência esta referência não aparece.

PALAVRAS-CHAVE: Comunicação; violência; invisibilidade da violência; violência doméstica; mulheres maltratadas.

\footnotetext{
* Projeto financiado por: Fundaçao FORD e CNPq.

${ }^{1}$ Pesquisadores do Grupo Violência e Gênero nas práticas de Saúde, Departamentto de Medicina Preventiva, Faculdade de Medicina, Universidade de São Paulo/FMUSP. <liliabli@usp.br>

** Os autores agradecem a Ivan França Jr., Elaine A. de Oliveira, Milena Dayan, Silvia Salvan Stracke e Andrea Felicissimo, participantes da pesquisa cujos dados são analisados neste artigo.
} 


\section{Introdução}

O silêncio $e$ a invisibilidade são temas associados à violência (Langley \& Levy, 1980; Heise et al., 1994; Heise et al., 1999; Rodriguez et al., 1996; Soares, 1999). Experimentar situações de violência, especialmente quando esta é de natureza doméstica e/ou sexual, tem se mostrado vivência de difícil revelação, quer no âmbito da pesquisa científica, quer no âmbito de práticas sociais de assistência, entre elas a Saúde. No plano dos serviços, igualmente se configura como um problema de difícil intervenção. Estudos trazem a violência, em geral, e a violência contra a mulher em particular, como temas culturalmente investidos (O'Toole \& Schiffman, 1997; Krug et al., 2002; Minayo, 1994), complexificando sua abordagem que, então, requer contornos particulares: locais, regionais, nacionais. A violência de natureza doméstica, por sua vez, amplia essa característica, ao situar-se no âmbito da vida privada e das relações familiares.

Emergindo como questão social importante mediante estudos dos conflitos familiares, a violência doméstica é mais conhecida por referência aos abusos e maus-tratos que sofrem as crianças, as mulheres, e os idosos. É possível ver nas agressões físicas e nos maus tratos de ordem psicológica, remanescentes da cultura que entendeu os castigos ou punições corporais $e$ a desqualificação moral ou a humilhação da pessoa como recursos de socialização e práticas educativas. Já o abuso sexual, de forma alguma tem essa mesma raiz. Não obstante, as dimensões física, sexual e psicológica mostram-se extremamente interligadas na violência doméstica. Esta é a situação da violência vivida pelas mulheres, recorte no qual vamos nos ater. De outro lado, se sofrer agressões e abusos por pessoas íntimas e próximas torna a violência contra a mulher situação próxima àquela das crianças $e$ dos idosos, são as questões de gênero, vinculadas às desigualdades nelas inscritas, que revestem as agressões e os abusos perpetrados contra as mulheres $e$ as meninas, $e$ tornam a violência contra a mulher evento específico. E neste caso, mais que em qualquer outro, vamos encontrar as delimitações das esferas psicológica, física e sexual borradas, exatamente por estarem envolvidas e resignificadas pelas questões de gênero.

Silêncios e invisibilidades são, pois, também questões de gênero, logo, são realidades que podem e devem ser abordadas no plano psicoemocional, sócio- cultural e ético-político, para uma aproximação primeira de sua complexidade. São as repercussões na condição de 'sujeito privado', de 'ser humano' e de 'indivíduo-cidadão', que devem chamar nossa atenção para a violência doméstica e sexual; são as conseqüências para a mulher cujas emoções, soberania, dignidade e direitos estão corrompidos e negados, $e$ que na Saúde ou em outros âmbitos da vida social, devem motivar os estudos e as políticas de assistência e prevenção.

Estudos sobre a violência contra a mulher já vêm sendo produzidos, notadamente a partir de 1990 (Schraiber Er d'Oliveira, 1999). São estudos quer do campo das Ciências Sociais e do Direito - os primeiros a abordarem essa questão no Brasil - quer do campo da Saúde.

No campo da Saúde, os estudos dirigem-se para pesquisas de caráter populacional ou em serviços de saúde, com objetivo de contribuírem também para a formulação de protocolos ou programas de assistência $e$ 
prevenção. De modo sintético podemos dizer que as questões que motivam as pesquisas são o reconhecimento da alta magnitude da violência, $o$ reconhecimento da violência como violação de Direitos e problema de Saúde Pública, e por conseqüência, a necessidade urgente de políticas e programas de intervenção (Heise et al., 1999).

De outro lado, a variedade de modelos de explicação, a terminologia diversificada e a polissemia dos termos, em razão da importante variação da percepção do fenômeno, nacional e internacionalmente, geram dificuldades para os desenhos de estudos, constituindo desafios atuais e pontos polêmicos na literatura científica. Esta passa a postular que as pesquisas evitem o uso do termo "violência", para não incorrer em sub-informação, quer pela não identificação da agressão ou abuso vividos com esse conceito (violência), quer pelo estigma que teme vir a sofrer a mulher que aceita a condição de ter sido "vítima de violência". Para resolver esse impasse, os estudos postulam perguntas diretas sobre agressões e abusos, explicitandose de quais atos e comportamentos se está querendo saber, inclusive detalhando-se a própria modalidade de agressão sofrida. Assim, quanto aos atos e comportamentos, podemos assumir que a violencia contra a mulher em geral diz respeito a assassinatos, estupros, agressões físicas e sexuais, abusos emocionais, assédio sexual, espancamentos, compelir a pânico, aterrorizar, prostituição forçada, coerção à pornografia, mutilação genital, violência por causa de dote, violação conjugal, violência tolerada ou perpetrada pelo Estado (crimes de guerra, por exemplo), todos eles dirigidos contra a mulher. Esta violência inclui, ainda, por referência ao âmbito da vida familiar, além das agressões e abusos já discriminados, impedimentos ao trabalho ou estudo, recusa de apoio financeiro para a lida domésticas controle dos bens do casal e/ou dos bens da mulher exclusivamente pelos homens da casa, ameaças de expulsão da casa e perda de bens, como forma de "educar" ou punir por comportamentos que a mulher tenha adotado (Heise et al., 1999).

Tornar tais atos ainda mais concretos, para a pergunta direta em pesquisa, é uma tarefa complexa e tem sido alvo de preocupação (Jewkés et al., 2000). As pesquisas têm se valido de alguns instrumentos já existentes, merecendo destaque a "Escala de táticas perante conflitos" (Conflict tatics scale ou CTS). Este instrumento, elaborado por Straus e Gelles (1979), respondeu à necessidade surgida em estudos sobre conflitos familiares, em que os autores partiam da idéia que a violência é uma das táticas possíveis de resolver os conflitos, quando assim a concebem os indivíduos em conflito. $\mathrm{O}$ instrumento permite o registro de táticas de entendimentos, agressão

${ }^{2} \mathrm{O}$ instrumento foi revisto e ampliado em 1996 por seus autores, que acrescentaram perguntas acerca de abusos e agressões de natureza sexual. verbal, agressão física ${ }^{2}$. Esta última é a que tem sido largamente usada, oferecendo a vantagem de discriminar atos já os apresentando em classificação de crescente severidade, tal como a usamos no presente estudo.

Se no âmbito da produção do conhecimento científico, a preocupação está voltada para a sub-informação, no âmbito da assistência o que se pondera, para além da sub-informação quando mulheres em situação de violência não contam tal situação aos profissionais que as atendem, é a questão do subregistro, situação em que há a revelação do vivido, mas o profissional não lhe dá importância e deixa de anotar no prontuário da paciente esse relato 
(Schraiber et al., 2000). Há, ainda, nesse âmbito da assistência, a preocupação com a não intervenção, mesmo em situações ou serviços que possuem protocolos de assistência ou estão filiados a redes de atendimento previstas (Coker et al., 2000; Salber \& McCaw, 2000; Waalen et al., 2000, Maiuro et al., 2000; Sugg et al., 1999; Sugg \& Innui, 1992).

Assim, entre o silêncio das mulheres e a invisibilidade do vivido no plano assistencial, as indagações correntes são: por que as mulheres não contam? Por que os profissionais não perguntam? Acresce-se, desse modo, à questão da omissão quanto ao vivido, os sub-registros e as recusas à tomada da situação violenta como problema da intervenção, que são atitudes cúmplices, igualmente ocultadoras da violência.

Pretendendo caracterizar melhor as questões conexas à revelação de violência vivida por mulheres, realizamos uma pesquisa que buscou conhecer a ocorrência de casos de violência doméstica e sexual entre usuárias de um serviço de atenção primária, bem como identificar as definições dadas ao termo violência e de que modo as mulheres que apontavam ter vivido episódios de violência denominavam este vivido. $\mathrm{O}$ estudo, portanto, aliou às perguntas sobre viver violência, aquela sobre a definição acerca da violência, por mulheres que a viveram ou não $e$, ainda, a pergunta sobre qual designação é conferida ao episódio por aquelas que o viveram.

O interesse pela questão da nomeação surgiu pela observação direta, na prática assistencial, da dificuldade apresentada pelas mulheres para apresentar o vivido. Assim, uma variante importante do silêncio, no sentido de matizar a idéia corrente de que as mulheres simplesmente não querem contar, surgiu na hipótese de que, quando querem contar, as mulheres não sabem exatamente a quem e como fazê-lo. Isto porque a revelação guarda importante conexão com o que move as mulheres para tal, e que pode ser o compartilhamento da situação vivida com pessoas íntimas e próximas, em busca do apoio familiar ou de amigos/as, mas pode ser também a busca de apoios institucionais. Tal seria o caso, quando há percepção da perda de um direito e a mulher vai à delegacia ou ao advogado, em busca da recuperação desse direito. Nossa suposição é a de que, quando há também a percepção de que é a situação de violência vivida a que responderia por agravos à saúde, ou danos físicos e/ou mentais, a mulher que vive esta situação demandaria o serviço de saúde em busca de ajuda específica e forma de lidar com seu sofrimento, ou para responder a suas necessidades de terminar com este sofrimento, melhorando sua saúde. Assim, o modo de revelar e o que exatamente será dito nesta revelação dependerá a quem, ou a qual instituição, a violência vivida será contada.

Não encontrar a forma de revelação ou não dispor de linguagem para tal é dificuldade que repercute, de imediato, na relação interpessoal de caráter assistencial, tal qual a relação usuária-profissional de saúde, em termos comunicacionais. Parte-se aqui, nesse sentido, da hipótese de que a dualidade "mulheres não contam e profissionais não perguntam" deve ser equacionada também em termos comunicativos, complementando as questões tratadas pela literatura científica e tecnológico-assistencial que, via de regra, trabalha silêncios e invisibilidade como conseqüência de medos,

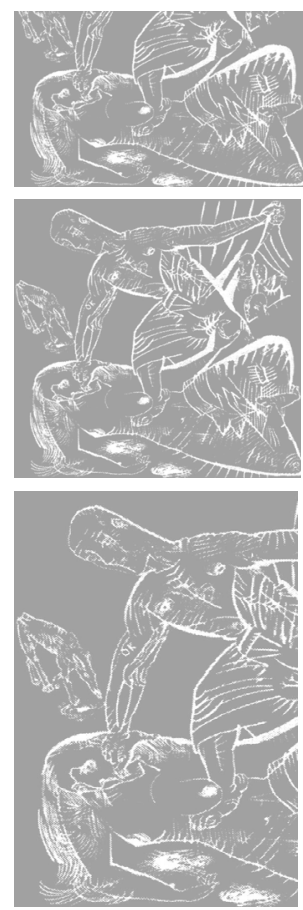


vergonhas, preconceitos ou descréditos (Hooks, 1997; Coker et al., 2000; Rodriguez et al., 1996; Hathaway et al., 2000).

Conforme a literatura, as mulheres não revelariam a violência sofrida ou porque sentem-se envergonhadas, em parte culpadas (Glantz \& Halperin, 1996), ou porque não se lhes dão crédito no que relatam e não recebem apoios institucionais para lidar com o problema, como revela um estudo sobre "os caminhos percorridos pelas mulheres que tentaram romper o silêncio" ou Rota Critica (Sagot, 2000). No campo da Saúde, os profissionais não perguntam porque não vêem qual a intervenção a ser feita, não se sentem habilitados, acham que não têm tempo para atender como deveriam, por ser este um problema por demais complexo, ou sentem o assunto muito próximo e, acima de tudo, não admitem que este seja um problema da atenção à Saúde (Sugg \& Innui, 1992; Salber \& McCaw, 2000).

Assim, estamos propondo acrescer às questões já levantadas, o fato de que, em especial no campo da Saúde, a dificuldade de expressar a violência vivida também é problemática da comunicação nas relações interpessoais, pela ausência de linguagem comum que dê conta de tornar esse vivido parte dos problemas que os profissionais de saúde concebem como atinentes à sua intervenção. Da perspectiva das mulheres usuárias dos serviços esta problemática se traduz em termos de "contar de modo a ser compreendida / acolhida" pelo profissional. Mas como fazê-lo se este profissional dialoga apenas na linguagem da doença? Pode a violência vivida ser revelada como adoecimento?

No campo específico da Saúde Mental, muitos adoecimentos são antes sofrimentos que patologias delimitadas na nosografia médica. Neste sentido, a noção de "sofrimento" poderia aproximar-se um pouco mais do vivido pelas mulheres em situação de violência. No entanto, também os sofrimentos nesta esfera mental tendem a ser transformados em ansiedades, depressões ou toda sorte de quadros mórbidos passíveis de intervenção no campo médico por meio de tecnologias conhecidas, e com a qual os médicos estão familiarizados. Em nome da "segurança na intervenção", da perspectiva do próprio profissional, os médicos não hesitam em simplificar (reduzir à sua nosografia) o quadro de sofrimento das pacientes.

É exemplar, no sentido da redução mencionada, como mostram os estudos de corte antropológico, a abordagem que fazem os médicos do problema de "nervos", ou o "nervoso" (Silveira, 2000). Nervoso é um vivido trazido por mulheres e medicalizado para a, e pela intervenção nos serviços de Saúde. Mulheres que "sofrem dos nervos" são, afinal, acolhidas no espaço da terapêutica médica e, pois, dos serviços de saúde, apenas em sua redução como alvo de uma tecnologia bem conhecida: o uso de medicamentos, na conhecida conexão "mulher que sofre dos nervos e receituário azul", isto é, a receita de medicação ansiolítica controlada.

Sofrer dos nervos e sofrer violência (Silveira, 2000) são situações que podem estar associadas e, talvez, uma parte da tradução da situação de violência vivida esteja sendo feita a luz desse "nervoso" e, desta forma, recebida nos serviços de Saúde.

O presente estudo não pretende esgotar essas questões. Ao contrário, é 
apenas uma forma inicial de trabalhar com dados relativos a relatos de episódios, definições de violência, autopercepção de sofrer violência e nomeações das agressões vividas. Buscamos, por aí, acrescentar à problemática das representações e percepções, a linguagem $e$ a comunicação como parte da questão da violência na esfera da Saúde, alertando para o que podem significar no plano das relações que são construídas pelas mulheres em situação de violência com os serviços assistenciais.

\section{Metodologia}

Trata-se de uma descrição primeira das questões de percepção, definição $e$ nomeação da violência vivida, integrantes de uma pesquisa mapeadora da violência entre mulheres usuárias de serviço de atenção primária (Schraiber et al., 2002), que teve por objetivo, na qualidade de um dos estudos pioneiros nessa aproximação, mais diagnosticá-la, demonstrar sua importância e características gerais, que construir modelos compreensivos de explicação da violência contra a mulher e suas relações com as práticas de saúde.

A investigação foi desenvolvida na região do Butantã, zona oeste do município de São Paulo. O serviço estudado foi o Centro de Saúde-Escola Samuel Barnsley Pessoa (CSEB), que é um Convênio Sistema único de Saúde /SUS - Secretaria de Estado da Saúde - Universidade de São Paulo/USP Faculdade de Medicina, participando, assim, da rede pública de prestação de serviços na cidade. Seu propósito central foi conhecer a prevalência de casos entre usuárias da atenção primária, caracterizando os tipos de violência sofrida, a severidade e os agressores. Foram entrevistadas 322 mulheres de 15 a 49 anos. Os episódios de violência foram questionados pela nomeação de atos específicos, conforme segue:

Para a violência interpessoal genericamente apresentada e tida como conexa à dimensão psicológica da percepção de abuso ou agressão: "Você alguma vez na vida sentiu-se maltratada, humilhada ou agredida por alguém próximo a você?".

Para a violência física: "Na sua vida adulta, alguém já bateu, deu tapas, chutou ou machucou você fisicamente de alguma outra forma? Por exemplo: ameaças de abuso incluindo o uso de arma; agressão ou violência contra objetos pessoais ou animais; tapas; empurrões sem lesões ou dor após o incidente; pontapés, contusões, socos, cortes e/ou dor após o incidente; contusões severas, queimaduras, fraturas; lesões na cabeça, lesões internas, seqüelas físicas; uso de arma, ferimento por arma."

Para a violência sexual: "Na vida adulta, alguém a forçou a ter relação sexual?" (vida adulta: maior que 15 anos).

Para evitar conexões diretas, intencionalmente a palavra violência, propriamente dita, não aparece nessas primeiras perguntas, tendo sido usada apenas quase ao final da entrevista, quando foi indagado: "Você considera que sofreu violência na vida?" (adulta ou não). Em seguida, foram apresentadas mais três questões abertas: "o relato de um episódio marcante"; "o nome que daria a este"; e "o que considera violência".

$\mathrm{O}$ presente trabalho centra-se nestas quatro últimas questões ${ }^{3}$.

$\mathrm{Em}$ termos conceituais trataremos da situação de violência contra

\footnotetext{
3 Para obter

espontaneamente a nomeação atribuída ao episódio e verificar a associação que a entrevistada faria entre as várias agressões que por ventura afirmara haver sofrido e o termo violência evitamos conexões diretas entre as perguntas. Também pedimos que definisse o termo violência de forma independente do relato, ainda que na seqüência da nomeação deste, $e$ independente das indagações por agressões de qualquer ordem. Coube a cada mulher, assim, colocar ou não na definição de violência qualquer modalidade de agressão que eventualmente afirmara haver sofrido bem como a maior ou menor explicitação do caráter doméstico, ou não, das agressões tidas como violência ou dos tipos possíveis de agressão.
} 
mulheres em geral, delimitada como atos de ameaça ou agressão psicológica, física e sexual. Mas também redefinimos a situação de agressão ou abuso vivido em termos de violência doméstica como atos realizados por familiares, companheiros ou ex-companheiros que conviviam ou não no mesmo domicílio; sendo a violência perpetrada ou não em domicílio.

Considerando que se revelar o vivido é difícil, também o é indagar por episódios de natureza tão sensível e delicada. Assim, tivemos cuidados éticos na investigação para poder obter uma melhor condição de revelação. $\mathrm{O}$ consentimento informado foi preparado com especial cuidado com a linguagem utilizada para deixar bem claros os compromissos de sigilo, privacidade e possibilidade de interrupção da entrevista a qualquer momento; serviços assistenciais estavam disponíveis para as entrevistadas se assim o desejassem; e aconselhamento e apoio psico-emocional foi oferecido às entrevistadoras.

\section{Resultados}

As 322 mulheres entrevistadas, usuárias de um serviço da rede pública do município de São Paulo, apresentaram como principais características sóciodemográficas na época da pesquisa: serem jovens (47,2\% têm entre 15 e 24 anos); 47,8\% se auto-definiram como de cor branca; e 59\% moravam com o companheiro. Quanto ao nível de instrução: 5,6\% eram analfabetas; $32,3 \%$ tinham até quatro anos de estudo; $33,8 \%$ até oito anos (fundamental completo); 19,6\% tinham completado o ensino médio; e 8,7\% tinham 12 anos ou mais de estudo. Quanto à ocupação: $36 \%$ declararam-se do lar; $41,9 \%$ estavam empregadas em trabalho regular (16,1\% como empregadas domésticas); 4,3\% em trabalho não regular; 4,3\% declararam-se estudantes; e $13 \%$ estavam desempregadas. Filhos: na época da pesquisa, $24,5 \%$ das entrevistadas estavam grávidas e $24 \%$ não faziam nenhum tipo de contracepção; $61,5 \%$ (198 mulheres) das entrevistadas tinham filhos, sendo que destas $72,2 \%$ tinham até dois filhos; $19,2 \%$ tinham até quatro filhos; $8,6 \%$ tinham cinco filhos ou mais.

Do total de mulheres entrevistadas, 44,4\% (143 mulheres) responderam ter sofrido pelo menos um episódio de agressão física na vida adulta, sendo que $76,9 \%$ desses casos foram perpetrados por companheiros ou familiares; $11,5 \%$ (37 mulheres) disseram ter sido forçadas a ter relações sexuais pelo menos uma vez na vida adulta, sendo $62,2 \%$ desses casos cometidos por companheiros e familiares. Quando questionadas sobre terem se sentido humilhadas, mal tratadas ou agredidas (violência psicológica) por alguém próximo, pelo menos alguma vez na vida, 55,6\% (179 mulheres) responderam que já haviam vivido este tipo de situação. Os dados revelam, ainda, que $69,6 \%$ das entrevistadas (224 mulheres) afirmaram ter passado por algum tipo de humilhação, desrespeito ou alguma agressão física ou sexual na vida adulta.

\section{Considera que sofreu violência?}

Quando indagadas se consideravam ter sofrido violência na vida, adulta ou não, das 322 entrevistadas, poucas mulheres (27\%) responderam positivamente. De outro lado, ao cotejarmos esta resposta com o total de 
entrevistadas que haviam respondido ter sofrido algum tipo de agressão ou abuso na vida adulta (224 mulheres), apenas $36,6 \%$ destas ( 82 mulheres) consideraram ter sofrido violência, ou seja: $63,4 \%$ das entrevistadas que vivenciaram algum desses episódios não perceberam o vivido como violento.

Note-se que cinco mulheres responderam negativamente às perguntas sobre agressões, apesar de considerarem ter sofrido violência alguma vez na vida (uma delas considerou violência um episódio de doença $e$ as demais sofreram agressões anteriores aos 15 anos, não respondendo positivamente às indagações de abusos ou agressões na vida adulta).

Outros dados obtidos: 37 mulheres responderam haver sofrido abuso ou agressão sexual; destas, $70,3 \%$ consideraram ter sofrido violência;

143 mulheres afirmaram haver sofrido agressões físicas; destas, 46,9\% consideraram ter sofrido violência na vida; 179 mulheres afirmaram ter se sentido humilhadas ou maltratadas (violência psicológica) e, destas, 40,3\% consideraram haver sofrido violência na vida. Ou seja: as que afirmaram ter sofrido abusos sexuais, em primeiro lugar, e físicos, em segundo, parecem ser aquelas que mais reconhecem a situação vivida como violência, sugerindo que esses abusos seriam os mais identificados como tal, ainda que em nenhum dos casos a associação entre o vivido e a consciência da violência tenha correspondido a $100 \%$ dos casos.

\section{Relato de um episódio marcante}

Para as 224 mulheres que disseram ter sofrido alguma agressão (física ou sexual), abuso, humilhação ou desrespeito, pedimos que relatassem algum episódio marcante. Destas, $35,7 \%$ não quiseram contar nenhum episódio e 64,3\% contaram algum episódio (144 mulheres), nos quais os agressores citados foram principalmente pessoas do âmbito familiar, como pode ser observado na figura 1.

Alguns dos episódios relatados ilustram bem a distância que se estabelece entre o vivido, a nomeação que se analisará adiante e a percepção de haver sofrido violência na vida.

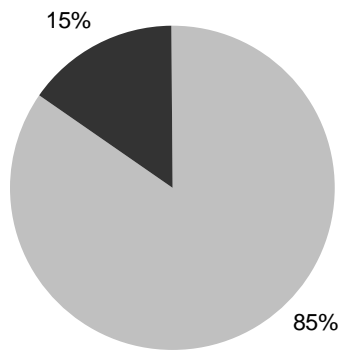




\section{Episódios anotados...}

Caso 1 - Paula

"Foi episódio único. Começou a discutir porque ele tinha amante. Uma noite ele demorou para chegar e ele esmurrou o rosto e ficou com hematomas no olho. Aí se separou logo após episódio. Ficou três meses voltou e juntou".

Caso 2 - Francisca

"Um irmão a pegou a força para fazer coisa que não deve, este irmão mais velho tirou sua virgindade e das duas irmãs. O irmão era separado da mulher, pegava as irmãs, levava-as para sua casa, trancava-as no quarto e as estuprava. Isso aconteceu mais ou menos nove vezes. Ela tinha 12 anos".

\section{Caso 3 - Joana}

"Um ex-noivo lhe deu três facadas com punhal, no braço e nas costas, que atravessou o peito. Teve que ficar internada para fazer drenagem. Diz que quase morreu. Conta que ele queria casar, marcou o casamento, mas ela se recusou e ele começou a ameaçá-la, até que aconteceu. Ficou um mês hospitalizada, até entrou em coma”.

Vale destacar que Paula, Francisca e joana estão entre as entrevistadas que não consideraram ter sofrido violência na vida.

\section{Que nome você daria a esta situação?}

Das 144 mulheres que relataram algum episódio, 46,5\% atribuíram a ele um nome; das que não nomearam o episódio, 17 (11,8\%) expressaram não saber ou não conseguir dar nome ao episódio. Entre as que nomearam, agrupamos as respostas em quatro categorias, descritas a seguir e ilustrado na figura 2:

Violência: lista os nomes violência, estupro e similares, como: humilhação, agressão brutal, barbaridade, situação monstruosa.

Justificativa/banalizadora: pinguço; atribulação; ciúme; loucura; drogas; imaturidade; malandro; discussão entre marido e mulher, de repente aconteceu;

Sentimentos de injustiça ou de tristeza: de injustiça - "fiquei revoltada com isso"; "se fosse um estranho, mas família"; de tristeza - sofrimento, pesadelo; um nome bem triste; "só sei que se não tivesse dois filhos, ia sumir sozinha no mundo"; vida cruel.

Auto-referidas: impaciência dela; estresse da gravidez.
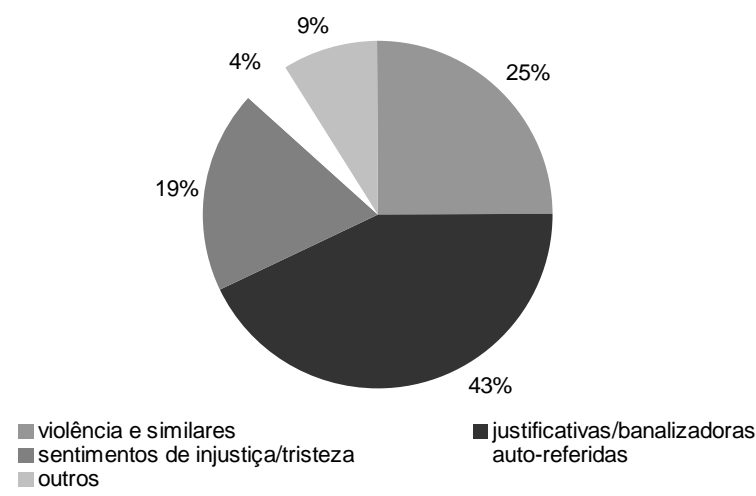

Figura 2 - Freqüência de nomeação do episódio de violência vivido, segundo tipologia 
Retomando a situação de Paula, Francisca e Joana cujos episódios foram acima apresentados, quando questionadas sobre "Que nome você daria a esta situação?", Paula respondeu: "Agressão, não violência", enquanto Francisca e Joana disseram não saber que nome dar.

\section{O que considera violência?}

\section{Falam as entrevistadas:}

"Palavras que machucam muito, dói mais que tapa. Os homens machistas que se acham superiores às mulheres querem bater não sabem conversar."

"Tem vários tipos: bater, machucar, empurrar, querer matar, maltratar crianças. Pessoas beber, se drogar. Temos que respeitar os outros. Mesmo não parecendo somos todos iguais."

"Matar."

Responderam a esta questão todas as 322 mulheres da amostra. As entrevistadas definem "violência" por situações diversas quanto ao tipo de agressão (física, sexual ou da ética das interações pessoais) e ao âmbito doméstico ou não doméstico da mesma. As respostas foram abertas e posteriormente codificadas, cabendo, desta forma, múltiplas categorias para cada uma. Respostas mais extensas acabaram preenchendo uma quantidade maior de categorias propostas como possíveis formas de definição. Quanto ao tipo de violência, 78,8\% das 322 mulheres referiram-se a agressões físicas para conceituá-la; 39,7\% apontaram situações referentes à ética das relações interpessoais - ações como agressões verbais, falta de respeito, obrigar a fazer o que não quer; e 24,2\% referiram-se à violência sexual. Quanto ao âmbito da violência, 46,9\% das 322 mulheres não especificaram seu caráter, deixando de nomear quem seriam os agressores e os agredidos; $32,6 \%$ referiram-se ao âmbito público - criminalidade, questões sociais, como desemprego e pobreza, trabalho, mídia; e apenas $26,1 \%$ das entrevistadas referiram-se explicitamente a situações do âmbito privado, especialmente agressões de pais contra filhos e marido contra mulher.

Voltando a ilustrar com os três casos relatados neste artigo:

\footnotetext{
Paula: "se ele agride sempre, deixa hematomas e ferimentos graves: mulher é mais frágil e é brutal o que fazem".

Francisca: "Muitas coisas que não devem acontecer, brigas, discussão com os irmãos... os pais são muito ignorantes com os filhos, ficam maltratando as crianças... os pais deveriam dar mais carinho para as crianças".

Joana: "É muito triste. Tenho medo das pessoas inocentes que morrem por aí sem ter feito nada, tenho medo porque tenho uma filha mulher".
}

\section{Discussão e conclusão}

A maioria das mulheres não considera que já viveu violência na vida, mesmo entre as que responderam haver sofrido agressões físicas ou abusos de ordem sexual ou psicológica. Confirma-se, assim, para fins diagnósticos ou de conhecimento nas pesquisas, a opção de se indagar sobre o tema por meio de perguntas diretas que descrevam atos concretos e específicos e não 
pelo termo violência. O significado da palavra violência pode variar bastante: uma das mulheres que considerou ter vivido violência não havia referido nenhum ato de agressão psicológica, física ou sexual, mas considerou doença e sofrimento uma forma de violência contra ela.

De outro lado, diante da afirmação de haver vivido agressões de qualquer ordem, e mesmo nas narrativas de episódios dramáticos e violentos, foi muito comum não considerar adequado nomeá-los de violência ou admitir ter sofrido violência na vida. Enquanto nas agressões sexuais verifica-se maior aproximação com o conceito violência, quando as entrevistadas definem esse termo, curiosamente citam de modo mais freqüente as agressões físicas.

São muitos os matizes que recobrem as representações da violência, e que parecem estar ligados tanto a uma diferenciação entre o que acontece com ela própria e o que ocorre em geral na sociedade, como a outras dimensões correlacionadas a esta diferenciação, como: o grau de implicação que teria a mulher no episódio de violência como sujeito em uma relação interpessoal $e$ a responsabilidade que daí adviria; a pressão de ordem sócio-cultural que estigmatiza a violência do âmbito doméstico; o não reconhecimento desta forma de violência como violação do direito.

Via de regra, violência parece ser um termo reservado à criminalidade $e$ usado para expressar o que ocorre no espaço público como, por exemplo, a violência geral das grandes cidades, cometida por desconhecidos, enquanto os problemas com vizinhos, colegas de trabalho e escola não são reconhecidos como violência. O termo também indica situação grave, o que, culturalmente, parece significar que a violência doméstica, embora concretamente severa, não é representada como tal. Chama a atenção que a violência do tipo sexual é a mais associada ao termo. Neste caso, o aumento da participação do agressor "estranho" no conjunto dos agressores, se comparado às violências física e/ou psicológica, estranho esse que pode ser até um conhecido mas não é um familiar, é um aspecto da violência sexual que pode estar contribuindo para seu reconhecimento como violência. Outra questão a se considerar é a natureza severa da violência sexual e o valor simbólico dado culturalmente a este tipo de agressão.

Uma parcela considerável das mulheres $(35,7 \%)$ não quis relatar o episódio vivido. Entretanto, entre as que aceitaram fazê-lo, a grande porcentagem de relatos foi de ocorrências no âmbito doméstico, reiterando os resultados das questões fechadas deste estudo, e também da literatura, que mostram uma preponderância deste tipo de episódios na violência contra as mulheres.

$\mathrm{O}$ mesmo se repete na nomeação da situação. A maioria das mulheres que relatou um episódio não deu um nome a ele $(53,5 \%)$, e uma parte $(11,8 \%)$ expressou não poder ou não conseguir fazê-lo. Ao analisar a nomeação dada, por sua vez, observa-se que, mesmo sem considerar como violência as agressões sofridas, quase todas entendem que não é certo, que não desejam a situação e reconhecem fortemente o sofrimento envolvido. Muitas tentam explicar o comportamento dos agressores. Outras ainda, ao dar nome ao vivido, banalizam o ocorrido como "coisa normal". Além disto, existe uma pequena parcela de mulheres que justifica a violência sofrida como uma 
falha delas mesmas, atribuindo a responsabilidade do vivido a si próprias. Também foi comum a referência a sentimentos de tristeza e desilusão, reforçando a dimensão mais "vitimizada" da violência.

Uma parcela pequena (25\%) reconhece o vivido como violência e assim o denomina. Entretanto, cabe destacar que poucas mulheres declararam, ao dar nome ao relato, que isto constituiria uma violação de direitos, o que demonstra ainda uma aceitação desses fatos como "atribulações" que fazem parte da vida, não estando colocada para a maioria a possibilidade de acionar os âmbitos jurídico-criminal e político-social, o que representa um obstáculo para a tomada de atitudes no sentido de transformar a situação.

Cabe destacar, ainda, que em nenhum relato ou mesmo na definição de violência, a saúde ou seu agravo foram lembrados, o que torna ainda mais premente o reconhecimento da situação pelos profissionais dos serviços de Saúde, posto a alta magnitude dos casos e as imensas repercussões já conhecidas para a saúde da mulher.

Veja-se que, ao definir o que é violência, apenas $26,1 \%$ referiram-se diretamente a agressões entre familiares na conceituação de violência. Como a pergunta era feita ao final da entrevista, que percorria questões do âmbito das relações interpessoais, chama a atenção que, como mencionado, o doméstico e as relações interpessoais perdem importância, a despeito da freqüência apresentada nos relatos e nas respostas às questões fechadas do instrumento de coleta dados.

Por outro lado, uma parcela das mulheres $(39,7 \%)$ lembrou das dimensões da coerção e dominação, e muitas insistem na importância desta forma de violência, ao apontarem para a dimensão psicológica como sendo situações até de maior constrangimento que a da violência física, por deixar "feridas que não cicatrizam".

Por fim, queremos apontar para a própria complexidade da percepção $e$ das representações que cercam o termo violência $e$ das conexões que isto acarreta para a decisão da mulher de enfrentar as situações de agressão vividas, bem como as possibilidades de estabelecer interações assistenciais mais produtivas nesse mesmo sentido. De um lado, nossa conclusão remete necessariamente para a importância de estudos ulteriores, que detalhem $e$ aprofundem as concepções acerca da violência pelas mulheres em geral e em especial pelas que a sofrem. De outro lado, a inclusão das temáticas comunicacionais e da melhor linguagem para alcançar os serviços e interagir com os profissionais parece ser de extrema urgência. Também da perspectiva dos profissionais de Saúde em geral, buscar uma linguagem compartilhada com as mulheres acerca de suas vivências, respeitando a delicadeza $e$ complexidade dessa situação e dando legitimidade ao sofrimento e aos sintomas decorrentes, é fundamental para atuar na promoção da saúde e garantia de direitos, tanto do ponto de vista ético da assistência, como também, pelo que mostra a literatura, para que suas ações sejam, de fato, mais resolutivas. 


\section{Referências}

COKER, A. L., DERRICK, C., LUMPKIN, J. L., ALDRICH, T. E., OLDENDICK, R. Help-seeking for intimate partner violence and forced sex in South Carolina. Am. J. Prev. Med., v.19, n.4, p.316-20, 2000.

GLANTZ, N. M., HALPERIN, D. C. Studying domestic violence: perceptions of women in Chiapas, Mexico. Reprod. Health Matters, n.7, p.122-7, may, 1996.

HATHAWAY, J. E., MUCCI, L. A., SILVERMAN, J. G., BROOKS, D. R., MATHEWS, R., PAYLOS, C. A. Health status and a health care use of Massachusetts: women reporting partner abuse. Am. J. Prev. Med., v. 19, n.4, p.302-7, 2000.

HEISE, L., PITANGUY, J., GERMAIN, A. Violence against women: the hidden health burden. Washignton: World Bank Discussion Papers, 1994. (n.255)

HEISE, L., ELLSBERG, M., GOTTEMOELLER, M. Ending violence against women. Population Reports, v.27, n.4, p.1-43, 1999.

HOOKS, B. Violence in intimate relationships: a feminist perspective. In: O'TOOLE, L. L., SCHIFFMAN, J. R. (Eds.) Gender violence. Interdisciplinary perspectives. New York: New York University Press, 1997. p.279-84.

JEWKES, R., WATTS, C., ABRAHAMS, N., PENN-KEKANA, L., GARCIA-MORENO, C. Ethical and methodological issues in conducting research on gender-based violence in Southern Africa. Reprod. Health Matters, v.8, n.15, p.93-103, 2000.

KRUG, E. G., DAHLBERG, L. L., MERCY, J. A., ZWI, A. B., LOZANO, R. (Eds.) World report on violence and health. Genebra: WHO (OMS), 2002.

LANGLEY, R., LEVY, R. C. Mulheres espancadas: fenômeno invisível. São Paulo: Hucitec, 1980. MAIURO, R. D., VITALINO, P. P., SUGG, N. K., THOMPSON, D. C., RIVARA, F. P., THOMPSON, R. S. Development of a health care providers survey for domestic violence: psychometric properties. Am. J. Prev. Med., v.19, n.4, p.245-52, 2000.

MINAYO, M. C. A Violência social sob a perspectiva da saúde pública. Cad. Saúde Pública, v.10, supl. 1, p.7-18, 1994.

O'TOOLE, L. L., SCHIFFMAN, J. R. (Eds.) Gender violence. Interdisciplinary perspectives. New York: New York University Press, 1997.

RODRIGUEZ, M. A., QUIROGA, S. S., BAUER, H. M. Breaking the silence. Arch. Fam. Med., v.5, p.1538, 1996.

SAGOT, M. Ruta crítica de las mujeres afectadas por la violencia intrafamiliar en América Latina: estudios de caso de diez países. Washington: PAHO, 2000.

SALBER, P. R., McCAW, B. Barriers to screening for intimate partner violence. time to reframe the question. Am. J. Prev. Med., v.19, n.4, p.276-8, 2000.

SCHRAIBER, L. B., D'OLIVEIRA, A. F. P. L., FRANÇA-JR, I., STRACKE, S., OLIVEIRA, E. A. A violência contra mulheres: demandas espontâneas e busca ativa em unidade básica de saúde. Saúde Soc., v.1-2, n.9, p.3-15, 2000.

SCHRAIBER, L. B., D'OLIVEIRA, A. F. P. L., FRANÇA-JUNIOR, I., PINHO, A. A. Violência contra a mulher: estudo em unidade de atenção primária à Saúde. Rev. Saúde Pública, v.36, n.4, p.470-7, 2002. 
SCHRAIBER, L. B., D'OLIVEIRA, A. F. P. L. Violência contra mulheres: interfaces com a saúde. Interface Comunic., Saúde, Educ., v.3, n.5, p.11-27, 1999.

SILVEIRA, M. L. O nervo cala, o nervo fala: a linguagem da doença. Rio de Janeiro: Fiocruz, 2000.

SOARES, B. S. Mulheres invisíveis: violência conjugal e novas políticas de segurança. Rio de Janeiro: Civilização Brasileira, 1999.

STRAUS, M. A., GELLLES, R. J. Measuring intrafamily conflict and violence: the conflict tactics (CT) scale. J. Marriage Fam., v.41, p.75-88, 1979.

SUGG, N. K., INUI, T. Primary care physician's response to domestic violence. JAMA, v.267, p.3157-60, 1992.

SUGG, N. K., THOMPSON, D. C., MAIURO, R., RIVARE, F. P. Domestic violence and primary care: attidudes, practices and beliefs. Arch. Fam. Med., v.8, p.301-6, 1999.

WAALEN, J., GOODWIN, M. M., SPITZ, A. M., PETERSEN, R., SALTZMAN, L. E. Screening for intimate partner violence by health care providers: barriers and interventions. Am. J. Prev. Med., v.19, n.4, p.230 7, 2000

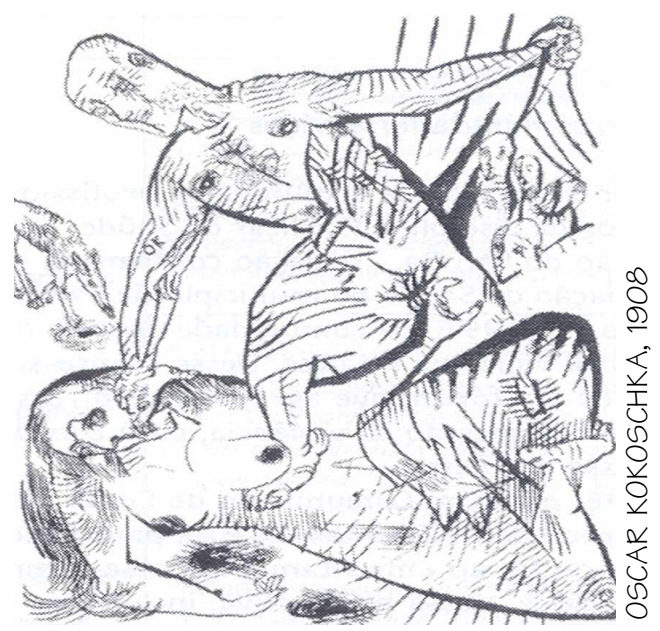

SCHRAIBER, L. et al. Violencia vivida: el dolor sin nombre, Interface - Comunic, Saúde, Educ, v.7, n.12, p.41-54, 2003.

Es difícil el relato de violencia sufrida por mujeres. Se trata de la invisibilidad de la violencia que afecta las relaciones usuarias - profesionales, creando impasses comunicacionales. Se trató de caracterizar este silencio, estudiando usuarias de atención primaria en la red pública de São Paulo, respecto a predominancia de violencia, a percepción de haber sufrido violencia, a definición de violencia en general y al nombre dado por quien la sufrió. Se entrevistaron 322 usuarias de 15 a 49 años, sobre agresiones física, sexual y/o psicológica, el agresor y la percepción de haber sufrido violencia, solicitando el relato de un episodio marcante, el nombre que daría a este y la definición de violencia en general. De las entrevistadas, $69,6 \%$ refirieron alguna agresión física, psicológica o sexual y, de estas, $63,4 \%$ no consideraron haber sufrido violencia en la vida; $64,3 \%$ relataron algún episodio marcante y $46,5 \%$ atribuyeron un nombre a lo vivido. La definición de violencia más común fue la de agresión física $(78,8 \%)$, seguida por la psicológica $(39,7 \%)$ y sexual $(24,2 \%)$. Se concluye que la mayoría de las mujeres que refirió alguna agresión no consideró haber sufrido violencia en la vida. Hubo gran dificultad en contar episodios y nombrarlos $y$, a pesar de que la mayoría de esos episodios sean do ámbito doméstico, en la definición de violencia esta referencia no aparece.

PALABRAS CLAVE: Comunicación; violencia; invisibilidad de la violencia; violencia domestica; violencia contra la mujer. 